\title{
Effective Health Services: Perspectives and Perceptions of Health Service Users and Healthcare Practitioners
}

\section{Krishna Regmi*}

School of Health, Sport and Bioscience, University of East London, London, UK

\section{Abstract}

Background: Since the declaration of Alma-Ata in 1978, many counties have achieved some tangible outputs in health sectors; there are still many challenges or barriers remaining in getting access to and utilisation of essential health services.

Objectives: To examine the meaning and understanding of Effective Health Services (EHS) from the perspectives of service users' and healthcare practitioners'.

Methodology: A mixed methods approach was undertaken. Data were analysed using a thematic framework for the qualitative data, and quantitative data were analysed using SPSS for descriptive statistics.

Results: Providing essential healthcare through a 'primary healthcare approach' is seen to be a central position in healthcare systems across the world. The study reveals that effective health services comprise: users' engagement and satisfaction; practitioners' skills and competencies; and service dynamics - policy of access, service availability, affordability and convenience in practice.

Conclusion: EHS has been accepted by users and practitioners as a means and end to improving or strengthening the quality of care services. This paper questions the assumption that though measuring users' and practitioners' understanding of healthcare is obligatory, it is equally important to provide an enabling environment in a way that meets quality and effective health services that might lead to improving better health outcomes.

Keywords: Effective heath service; Quality service; Patient satisfaction; Access to care; Primary health care; Nepal

\section{Introduction}

It has been well emphasised that delivering better health services to poor people lies at the centre of many governments' health polices in both developing and developed countries [1-3]. Since the declaration of Alma-Ata in 1978, many counties have already achieved some tangible outputs in health sectors (e.g. prevention of communicable diseases, reduction of maternal and infant mortality, eradication of smallpox, an initiative towards the eradication of polio, advancements in medical technology, and wider participation of service users in health programming), there are still many challenges or barriers remaining in getting access to and utilisation of essential, appropriate and quality healthcare services in the light of prevailing countries' socio-economic and cultural contexts [4]. Nepal, for example, despite launching a safe motherhood programme as an essential health package delivered through 'primary healthcare' mainstreaming, is still the country which faces the highest maternal and child mortality in the world $[2,5]$. WHO [6] states that 'a good health system delivers quality services to all people, when and where they need them' (p.x). WHO [7] recognises quality as a key driver to improve health outcomes and provide greater efficiency in delivering health services. Nevertheless, providing effective and quality health services in the local community has never been an easy task for any government, as the meaning of 'effectiveness' is contested and complex in nature, and varies from disciplines to fields that underscore the different senses that bring some degree of ambiguity in practice. As many literatures suggest that effectiveness is often measured by numerical matrices - for example, achieving the established indicators, and measuring the proportion of spent budgets vs planned activities - as a result it does not provide a true picture of the health services and, most importantly, the elements of inclusive and integrative view of peoples' perspective are grossly ignored or neglected in health services, in particular the users' and practitioners' views in the current state of health knowledge [2,8-10]. It is, therefore, important to examine the meaning of effectiveness in terms of its nature and scope. In Wilkin et al. [11] view, effectiveness should be determined by the interpretation of users' perspectives, and whether the services have had any effects on individuals' and communities' health. Wilkin et al. [11] further argue that user' perceptions or views of their health are rather subjective, determined by the 'realms of needs for health care and final outcomes'.

Halim et al. [12] argue that in Nepalese healthcare systems, particularly maternal and childcare, there is a lack of understanding of both the supply and driven sides of healthcare provisions. They state that: 'limited maternal and child health gains in the face of supplyinduced increases in the health services indicate that a comprehensive understanding of maternal and child health demands not only an analysis of supply side, but also a no less comprehensive understanding of the demand driven utilisation of maternal health care' (p.243). Effectiveness in some context is considered an intermediate goal of measuring health services and a measure of the health provision function [9]. In a similar vein, it has been argued that effective health relates not only to making services accessible and affordable to the people, but also developing and then delivering health services tailored to meet peoples' healthcare needs, demands and interests [8]. In the light of the literatures review, users' satisfaction is therefore considered

*Corresponding author: Krishna Regmi, School of Health, Sport and Bioscience, University of East London, London, UK, Tel: +44(0)2082234578; E-mail: Krishna@ uel.ac.uk

Received May 10, 2012; Accepted June 16, 2012; Published June 18, 2012

Citation: Regmi K (2012) Effective Health Services: Perspectives and Perceptions of Health Service Users and Healthcare Practitioners. Primary Health Care: Open Access 2:117. doi:10.4172/2167-1079.1000117

Copyright: (c) 2012 Regmi K. This is an open-access article distributed under the terms of the Creative Commons Attribution License, which permits unrestricted use, distribution, and reproduction in any medium, provided the original author and source are credited. 
as an intermediate outcome of service effectiveness [1,2]. Wilkin et al. [11] support this notion by looking at two different ways:

First, it is argued that satisfaction with care will be directly related to the final outcomes of that care, and second, satisfaction of the consumers should be a legitimate objective of the providers of a health service.

Wilkin et al. [11] however, equally warn that there are still some problems in measuring users' satisfaction in healthcare: first, there might be different views in terms of defining the term 'satisfaction' in terms of the content, aspect and context; second, it might be equally difficult to see the linkage between satisfaction and expectations. Therefore one can argue that bringing services closer to the local people in meeting their healthcare needs and interests is an important role of healthcare practitioners; for example, how they plan, whom they plan with on what, and how much leeway they have in making decisions and then tailoring existing resources to address local peoples' health problems. Several authors [13] noted that making service autonomous i.e. free from central control, and people's involvement, are considered important vehicles for developing effective services. Similarly, Regmi et al. [8] comment that responsiveness in the service development element and its proper management would be considered as an important step.

It is surprising how little attention has been paid in the research literature to assessing, examining and understanding the meaning of 'effectiveness' in healthcare services. Therefore this paper aims to examine and understand the meaning of 'effective' health services from the perspectives and perceptions of both health service users and healthcare practitioners.

\section{Methods}

A mixed methods approach with sequence into two phases was utilised. For the quantitative arm, the researcher utilised the Likert scale with 25 items of five ratings with service users'-related health services effectiveness on the aspects of individuals, communities and health systems functions. Respondents were arrayed along a scale ranging from 1 -'Strongly agree' to 5 - 'Strongly disagree' with a series of statements to which they indicate their level of agreement or disagreement [14]. Some scales' statements were adopted and modified from Wilkin et al. [11] Completing this questionnaire typically took approximately 30-40 minutes per individual. On the qualitative arm, focus group discussions and in-depth interviews (FGDs/IDIs) were conducted, using a topic guide (Box 1), amongst purposively selected (non-probability) samples $[15,16]$ with healthcare practitioners, with the aim of exploring their understanding and conceptualising of the term 'effectiveness' and examining the factors influenced access to and utilisation of primary (local) health services in selected districts in Nepal. The purpose of undertaking the qualitative component of the study was that this approach provides the researcher with some 'individualised and contextualised phenomena within respondents' social world' $[17,18]$. Cotterill [19] argues that this approach allows 'subjective phenomenon capturing through objective manner' (p.54). Similarly, Oppenheim [20,21] argues that the qualitative approach also allows the respondents some degree of freedom - to capture their ideas, views and perceptions without any restriction in response to the research questions. Data were analysed using a non-linear scaling process based on non-parametric item response theory [22]. The benefits of using this approach are that it would provide a method for assessing the dimensionality of a set of data [23,24] as well as minimising potential problems that might occur while analysing the categorical data using linear statistical methods [25].

\section{Box 1 Topic guide for interviews/discussions}

How long have you been in this post?

What has been your experience of managing the local health services?

(Prompts: planning, assessing and delivery of health services; any bad/ good experience, if say so, why?)

\section{How effective are the local health services?}

(Prompts: understanding of effectiveness, ask which healthcare service is more effective (e.g. immunisation, TB, Safe motherhood) and why? If they say one or two health services limited/non-effectiveness, what would be their reasons?)

What sorts of challenges have you encountered while planning and delivering effective local health services in the current context?

(Prompts: poor resources, people, political commitment, un-accepting bureaucracy, controlled decision-making process, service planning, poor supervision and monitoring etc)

How do you think we can improve health services to make them more effective?

(Prompts: in making services more responsive towards meeting people's health needs and interests)

Qualitative data were processed and analysed via inductive analytical methods for descriptions and interpretations using NVivo8 to develop themes, sub-themes, codes and sub-codes [26] whereas SPSS was employed to analyse descriptive statistics of quantitative data generated from the Likert scales. The findings from both methods were triangulated to strengthen the validity as well as truly reflect the study findings [27].

Field instruments (Likert scale questionnaires and topic guides) which were developed in English were translated into the local language (Nepalese) in some cases where respondents did not understand the meaning of questions or themes adequately. They were then backtranslated into English [28]. Peer debriefing/member checking was also utilised to assess and verify the trustworthiness of field data [29]. Ethical approval was granted from the local ethics committee, and ethical consent was also obtained before administering the study questionnaire and initiating the discussions. This research was undertaken between June and August 2011.

\section{Results}

125 questionnaires were given out, as four research assistants observed twice, and $100(80 \%)$ of the questionnaires were returned. Non-respondents were not re-contacted. In the qualitative arm, we conducted three focus group discussions and five in-depth interviews with healthcare practitioners $(n=13$; three physicians (D), five paramedics $(\mathrm{P})$, two medical trainee doctors $(\mathrm{Dt})$, and three nursing staff $(\mathrm{N}))$. Overall, 54 women $(48 \%)$ were included in the study, and the mean age was 45.35 (range 20-50, mean 1.69, SD 0.982). Table 1 reports the demographic attributes of the respondents. The results are presented around four main themes that emerged from the data: (i) attitudes towards effective health services; (ii) quality of health services; (iii) barriers or challenges related to access/use of services; and (iv) areas to improve. Each of the above main themes is illustrated with excerpts from participants. Excerpts include their code, gender and age in parentheses. The code is used in place of pseudonyms.

\section{General attitudes towards effective health services}

Both health service users and healthcare practitioners shared a 
common understanding about the perception of 'effective' health services, and they viewed that an effective service considers the aspects of satisfaction $(62 \%$, mean 2.69 , SD 1.568$)$, appropriate to the needs of the individuals and community (97\%, mean 1.57, SD 0.655), and better health outcomes (97\%, mean 1.58, SD 0.645) (Table 2).

\section{Quality of health services}

Of the service users $(n=100)$, the study reported the quality (items: $2,14,15,16,17,18)$ as a means of delivering better health services. More than $80 \%(n=90)$ of the respondents argued that quality is determined by a number of attributes, ranging from the level of healthcare practitioners' skills and competencies, their commitments and motivations, to how far the provided services address the issues of diversities - disability, handicaps, gender and equity in health. This study also highlighted that healthcare practitioners' interpersonal and interprofessional skills yield the degree of quality in service delivery (75\%, $\left.\mathrm{X}^{2}=25.52, \mathrm{df}=3, \mathrm{p}=000\right)$.

The interview component of this study also addressed the aspects of quality in planning, delivery health services and the view of quality and effectiveness from health practitioners. A majority of the participants $(85 \%, n=11)$ viewed that quality is linked with the performance and satisfaction of both users and providers. One respondent put quality in this way:

Quality of healthcare is a product of satisfaction, access and utilisation of health services (DM40)

The same respondent further adds that:

In global terms $\ldots$ it is a concrete form of individuals and institutional policies and programmes (DM40).

\begin{tabular}{|c|c|c|}
\hline Category & Quantitative $(n=100)$ & Qualitative $(n=13)$ \\
\hline \multicolumn{3}{|l|}{ Gender } \\
\hline Male & 51 & 8 \\
\hline Female & 49 & 5 \\
\hline \multicolumn{3}{|l|}{ Age, years } \\
\hline $20-30$ & 59 & 1 \\
\hline $30-40$ & & 22 \\
\hline $40-50$ & 10 & 4 \\
\hline$>50$ & 9 & - \\
\hline \multicolumn{3}{|l|}{ Education } \\
\hline SLC/GCSC & 38 & 2 \\
\hline Intermediate/A level & 20 & 4 \\
\hline UG/PG level & 5 & 7 \\
\hline Illiterate & 37 & - \\
\hline
\end{tabular}

Table 1: Demographic attributes.

\begin{tabular}{|c|c|c|}
\hline Items & $\%$ Agree (strongly)* & Mean [SD] \\
\hline \multicolumn{3}{|c|}{ Effective services means } \\
\hline Access & 95 & $1.04[0.198]$ \\
\hline Easy to get & 81 & $1.10[0.302]$ \\
\hline Whenever I need & 60 & $1.40[0.492]$ \\
\hline Satisfy & 48 & $1.52[0.502]$ \\
\hline Appropriate & 52 & $1.48[0.502]$ \\
\hline Positive outcomes & 42 & $1.58[0.496]$ \\
\hline
\end{tabular}

* Items were measured on a five-point scale (1- strongly agree and 5- strongly disagree). For the fraction that agreed (strongly) responses in the categories related to the aspects of effectiveness were merged.

Table 2: Service users reported the effective aspects of health services.
When asked what sorts of measures are in place to assess the effectiveness of health services, a few respondents said:

We have regular staff meetings [monthly] and performance review meetings biannually where we discuss, we share best practices, and invite users to their overall experience of care (DM41, PF12, NM38).

It has been discussed that the health service performance or service outcomes were often shared widely among healthcare professionals, staff members and management committee. Additionally, they would formally submit it to the district health officer and sometimes these would be forwarded to the centre [Department of Health Service]. A few health professionals link effectiveness of health services with the costs and available healthcare provisions. One argues that:

Though healthcare provisions was on the doorstep, people didn't access it because they thought that essential healthcare is not free, as they have to go and purchase expensive medications from the private pharmacy/medical shops (PF37).

During the interview component of the study, the majority of the health practitioners view $(80 \%, n=10)$ that professionals' ethics and morality should relate to the care of the people. They also added that many practitioners forget about their duty being health workers in the community and they instead open up their private clinics/shops. They did encourage users to purchase medications from their shop and/ or simply referred them to their own private clinics/shops for further consultations. One respondent viewed it as simply

An ignorance of their professional obligation (DtF27).

\section{Barriers or challenges to related services}

Though more than $90 \%(n=101)$ participants were satisfied with the local health services in terms of their service access, availability, and convenience of service location (items: $1,3,5,6,7,8,9,10,11$, 12), these participants also raised some key barriers or challenges faced while accessing and using local health services. The main challenges that were reported were that they had to wait a relatively long time (ranging from three hours to 14 days). In addition, they reported that it was very difficult to get service at short notice, even to get emergency/

\begin{tabular}{|l|l|l|}
\hline \multicolumn{1}{|c|}{ Items } & \% Agree (strongly) & Mean [SD] \\
\hline Long waiting times & 97 & $1.03[0.171]$ \\
\hline Hard to get there at short notice & 91 & $1.09[0.288]$ \\
\hline Lack of specialists & 70 & $1.29[0.457]$ \\
\hline $\begin{array}{l}\text { Opportunities for not involving in planning/ } \\
\text { engagement }\end{array}$ & 73 & $1.27[0.446]$ \\
\hline Limited/no role in decision-making & 76 & $1.24[0.429]$ \\
\hline
\end{tabular}

* Items were measured on a five-point scale (1- strongly agree and 5- strongly disagree). For the fraction that agreed (strongly) responses related to the challenges or problems categories were merged.

Table 3: Service users reported the challenges or problems while accessing and using health services.

\begin{tabular}{|l|l|l|}
\hline \multicolumn{1}{|c|}{ Items } & $\%$ Agree (strongly) & Mean [SD] \\
\hline Training and development & 100 & $1.00[0.000]$ \\
\hline Longer office hours & 75 & $1.20[0.402]$ \\
\hline Role in planning and participation & 83 & $1.27[0.446]$ \\
\hline Issue of disability, handicaps and gender equity & 38 & $1.61[0.490]$ \\
\hline
\end{tabular}

* Items were measured on a five-point scale (1- strongly agree and 5- strongly disagree). For the fraction that agreed (strongly) responses related to the areas of improvement categories were merged.

Table 4: Areas to improve health services. 
casualty services. The common frustration that they reported was that there was no specialised manpower at the local health centre, therefore if any serious conditions occurred they then had to rush to the district or zonal hospitals, or even sometimes the national hospitals for emergency cases needing specialist services. Similarly, more than half (55\%) of respondents (service users) reported that they were never invited to engage/participate in local planning, management and delivery of their local health services, and they argued that the local health services or plans did not address the local healthcare needs $(62 \%$, mean 2.80, SD 1.48). This study further reveals that local people have very limited roles in the planning and local decision-making process (58\%, mean 3.31, SD 1.66) (Table 3).

While discussing healthcare practitioners regarding their challenges or barriers to planning and delivering of local health services, several respondents $(92 \%, \mathrm{n}=12)$ reported about the lack of continuing professional development (CPD) and limited opportunities for career advancement or progression. One respondent argued that:

I have never been offered the chance to go abroad to get a higher education, nor invited for the national level training programme (PF32).

\section{The same respondent further went on to say that}

When she met DPHO [line manager] during the annual review, $s /$ he [DPHO] recorded on the staff development folder and assured her... but it has never materialised yet (PF32).

Another respondent raised the point that:

I have been in this same post [Senior Health Assistant] for more than 10 years...when I submitted by performance file [portfolio] to get promotion...I was told that I have to wait for another five years. I did not know why our health systems are not responsive to addressing healthcare practitioners' interests. In fact, I am now very de-motivated and am thinking of quitting the job...very demoralised (PM48)

The study has clearly highlighted the lack of professional training and development opportunities in practice. When asked whether they had any formal training prior to entering into their respective working positions, one participant's remark was that:

It was one of the grossly ignored dimensions in the Nepal health system.' (DM54)

\section{Another respondent stated that:}

This is one of the outcomes of the bureaucratic mentality of the centre. (PM53)

The interviews and discussions with healthcare practitioners clearly highlight that the process of reviewing or appraising staff development opportunities in terms of their professional development as well as career progressions are noted to be very limited. As a result, it might erode healthcare professionals' morale at work, which would have a negative impact on performance [30,31].

\section{Areas to improve}

Most of the respondents argue that delivering 'responsive' services is the key principle of the local healthcare centre. One respondent pointed out that:

We should do whatever we can to make our health services more responsive and help our community's health better (NF34).

Service users also rated highly their understanding of responsiveness in a similar line of healthcare practitioners, as they perceived that healthcare workers working in the primary (local) health centres, for example, doctors, nurses and other allied health workers, need to be more thorough in training and in examining peoples. They also reported that the current opening times of health centres were very limited $(10.00-2.00 \mathrm{pm})$ and they suggest that they should be a bit longer, at least until $4.00 \mathrm{pm}$. Similarly, they agreed (strongly) that they should be invited to participate in the local planning and decisionmaking process while managing the local health services (Table 4). The summary of the Likert scales data - descriptive analysis has also highlighted these attributes (Appendix - 1).

In addition, nine out of thirteen (69\%) healthcare practitioners also reported that although there are some policies for staff retention and progression, the career progressions and advancements are very much on the papers not in the practice yet. A third say that the central government (Department of Health) - is still playing this role, which should not be the case, as the LSGA of 1999 has clearly outlined that the roles of staff development and progressions should be given to the local authorities, districts and sub-district levels, and $\mathrm{DOH}$ would engage very much in policy directives [32]. The majority of the participants $(78 \%, n=88)$ who contributed to the study were aware about the strong linkage between motivation of staff and the effect on delivering effective healthcare. West et al. [31] reported that 'Organisations where staff report feeling involved in decision making show correspondingly high patient satisfaction rates, and lower rates of infection, patient mortality, staff absenteeism and staff turnover' (p.10).

\section{One argues that:}

Discrimination is always linked with low performance at work, and that also leads to poor user satisfaction.' She further said, 'staff morale improves when they know their managers or organisations [DOH] are interested in them as important members of the healthcare team (NF43).

\section{Discussion}

The study results show that 'effectiveness' of health services is complex in nature as it is difficult to measure in real terms. As Borrill et al. [30] argue, a health system comprises a range of stakeholders (healthcare professionals, service users, heath management committees, local communities, including the policy-planners and decision-makers), and they have their own interpretations of service effectiveness. Similarly, several authors argue that there are different approaches, perspectives and philosophies of care which exist amongst different professionals or practitioner groups in terms of understanding and measuring quality and effectiveness of healthcare in practice [9,33]. As Wilkin et al. [11] point out, effectiveness is often determined by whether the healthcare needs have been appropriately met, and the outcomes have become positive. Therefore one can argue that a positive outcome after interventions in meeting peoples' healthcare needs is considered as effective care. Wilkin et al. [11] still question whether we can consider 'effectiveness' as some form of product, due to the 'relationships between needs, healthcare provisions, and outcome'. Aiken et al. [34] state that the staffing issue has been considered as one of many multi-dimensional factors related to users' health outcomes in any organisational context. Mpinga and Chastonay [35], for example, argue that effective health should be viewed as a 'right to health' which is determined by the availability and accessibility of health services, including the quality of healthcare. WHO [36] defines quality as:

A broad ranging concept, incorporating in a complex way individuals' physical health, psychological state, level of independence, 
social relationships, personal beliefs and their relationships to salient feature of the environment.

Quality has also been considered as whatever is to a given individual at any given time [37]. It has been argued that effectiveness is often linked with the satisfaction of services which ultimately impact on the health services management [9]. This study attempts to examine both approaches of services. Mpinga and Chastonay [35] also noted that both effectiveness of and satisfaction with services would 'allow the interpretation of patients' view into the functioning of the health sector' which helps to assess (identify), analyse/clarify and prioritise the problems for appropriate action.

It has been argued that that access to utilisation of healthcare depends on the aspects of service provisions (available), and accessibility, as well as affordability. Leatherman et al. [38] state that quality health services would bring better health outcomes. They also suggest that 'high-quality health care ought not to be an extravagance reserved only for the more affluent countries; it is now an imperative to strengthen health systems in developing countries'. Similarly, several studies reported that effectiveness and delivery of quality healthcare would be determined by both healthcare professionals' burnout and the patient satisfaction with the healthcare received, as well as approaching for joint planning and decision-making [30,34]. In West et al. [31] view, 'to deliver good service you need to ensure that staff feel empowered and nurtured, whatever their background'. Aiken et al. [34] large scale covering nine countries' studies reveal that 'Hospitals with consistently better work environments had lower burnout, lower likelihoods of having nurses who were dissatisfied with their jobs'. Indeed, this was true in many respects in different health systems to bring better health outcomes to the service users.

One of the key strengths of this study is that it represents the voices of some service users and this reflects the experience of users and healthcare practitioners. As Wilkin et al. [11] suggest, there are two main ways to assess users' satisfaction: first, examining and exploring users' view of the care they received and the practitioners who delivered the services (direct approach); second, seeking general opinions, personal experiences, service satisfaction, and service responsiveness including inter-professional communication with health professionals (indirect approach). From the methodological point of view this study has some strength in terms of using a mixed methods approach, and the findings have been triangulated to bring validity and rigour. It has been argued that the use of a Likert scale might be an appropriate and original tool for the 'weighting of items by allowing each respondent to produce individual weightings' [11].

Another strength of the study was the development of a conceptual framework (Figure 1) of effective health service, as it suggests that effective services embed into two important dimensional aspects human and non-human (physical) aspects of health. One important thing that emerged from the study was that quality is often connected with effective care, and effective health is determined by a number of factors or characteristics, i.e. service availability, accessibility, affordability and acceptability; and it will be shaped by the degree of engagement of both users and healthcare providers; managing potential barriers or challenges to access and utilisation and then scaling up/strengthening appropriate health services with formulating appropriate strategies, policies and provisions in practice with the view of integrating patients' satisfaction in making service effective.

Despite some useful findings, this study has some limitations that need to be explored and discussed. First, this small-scale study was conducted in one district (out of 75) with limited sample sizes ( $\mathrm{n}=113 ; 100$ service users and 13 healthcare practitioners) to assess and explore both users' and providers' perceptions about the effectiveness of health services. It can, therefore, be argued that the findings from this particular study might not be safely generalised across the nation and across the neighbouring regional countries - India, Pakistan, Bangladesh and China - as these might have different socio-economic and geo-political landscapes, as well as diverse healthcare foci. Second, it has been consistently reported that there is a lack of a clear theoretical - methodological and conceptual framework to assess the effectiveness of services in health [11] therefore the purposed multiple methods Likert scale, focus group discussions and in-depth interviews - have been envisaged to capture the wider understanding of both users' and providers' views about the subject matter. Third, this study lacks the perspectives of people in general, including the policy-planners and decision-makers, therefore it can be argued that representing these wider audiences' [24] views would bring more robust findings. In addition, using Likert-scale questionnaires also noted three problems it is resource-intensive in terms of time and resources, and it demands a list of respondents in terms of sample size, as well as what respondents

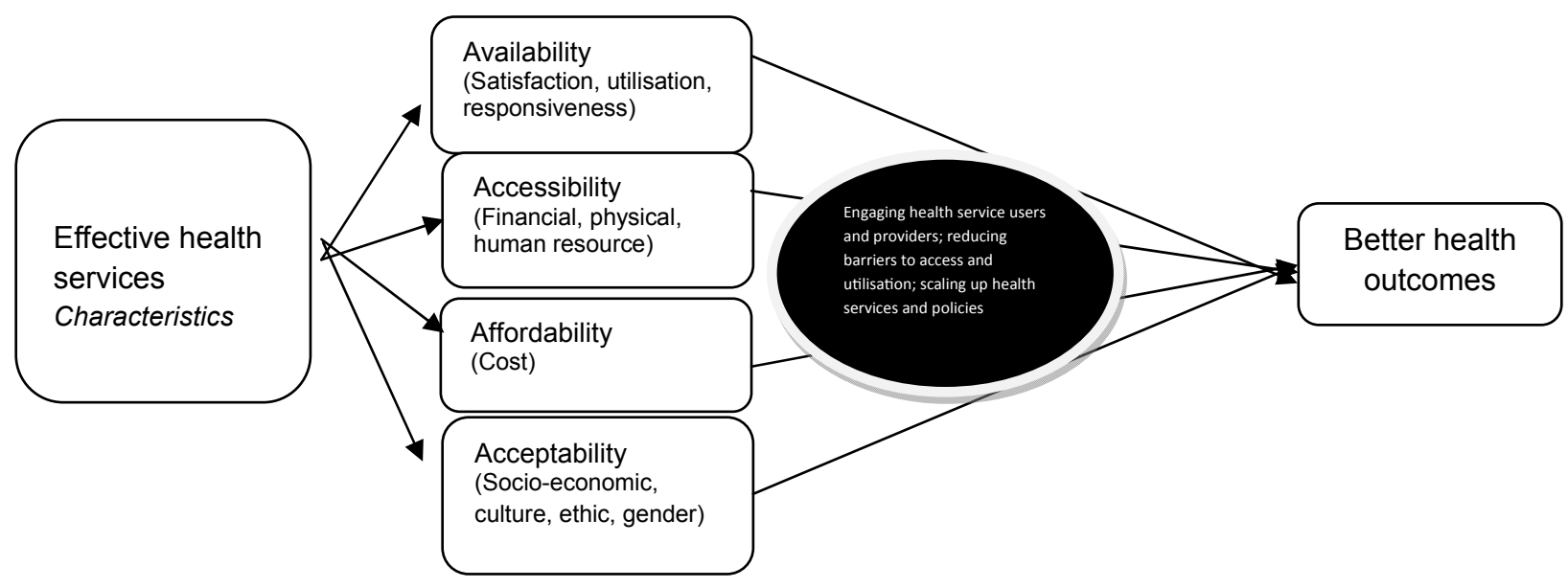

Figure 1: Effective health service leads better health outcome. 
Citation: Regmi K (2012) Effective Health Services: Perspectives and Perceptions of Health Service Users and Healthcare Practitioners. Primary Health Care: Open Access 2:117. doi:10.4172/2167-1079.1000117

Page 6 of 7

are being asked to do [24]. Finally, it is not an externally-funded study, therefore it prevents the researcher from reaching wider audiences within and across the districts and communities. This study, however, would benefit from being related with a larger sample size, and a wider geographical location with diverse audiences, including the local and national-level policy-planners and decision-makers.

\section{Conclusion}

Although 'primary healthcare' has been adopted as a universal and essential healthcare approach, many barriers still exist in health systems $[1,2,4]$. This study has explored some problems and potentials while accessing and utilising local health services. The study highlights that both healthcare professionals' satisfactions and motivation, and service users' wider engagement in health services planning, are the key attributes to developing and delivering effective healthcare services. Though many respondents appreciate the importance of feedback from both users and providers on the overall experience of healthcare, it is equally important to make the necessary changes or improvements in organisational aspects to bring about positive outcomes in practice. This paper concludes that tripartite relationships between health providers, health service users and other enabling environments associated with the institutional-organisational policies are central not only to deliver health services effectively, but also in developing more responsive healthcare - tailoring to meet the needs of the people to get better outcomes.

\section{Acknowledgements}

The author gratefully thanks the service users and healthcare practitioners who took part in this study. The support received by the research assistants and senior health assistant was greatly appreciated.

\section{References}

1. World Health Organisation (2008) Primary Health Care Now More Than Ever. WHO, Geneva

2. World Health Organisation (2004) Making Services Work for Poor People WHO, Geneva.

3. Wagstaff A (2002) Poverty and health sector inequalities. Bull World Health Org 80: 97-105.

4. Sibley LM, Weiner JP (2011) An evaluation of access to health care services along the rural-urban continuum in Canada. BMC Health Serv Res 11: 20.

5. UNICEF (1996) Children and Women of Nepal: A Situation Analysis. Kathmandu, Nepal, UNICEF.

6. http://www.who.int/topics/health_systems/en/

7. World Health Organisation (2007) Everybody's Business: Strengthening Health Systems to Improve Health Outcomes. WHO, Geneva.

8. Regmi K, Naidoo J, Pilkington PA, Greer A (2009) Decentralization and district health services in Nepal: understanding the views of service users and service providers. J Public Health (Oxf) 32: 406-417.

9. Murray CJ, Evans DB (2003) Health Systems Performance Assessment: Debates, Methods and Empiricism. World Health Organisation, Geneva.

10. World Health Organisation (2012) Dying for Change. WHO, Geneva.

11. Wilkin D, Hallam L, Doggett MA (1992) Measures of Need and Outcome for Primary Health Care. Oxford University Press, Oxford, New York.

12. Halim N, Bohara AK, Ruan X (2011) Healthy mothers, healthy children: does maternal demand for antenatal care matter for child health in Nepal?. Health Policy Plan 26: 242-256.
13. Peckham S, Exworthy M, Powell M (2005) Decentralisation as an Organisational Model for Health Care in England. SDO, London.

14. Bryman A, Hardy MA (2009) The Handbook of Data Analysis. Sage Publications Ltd, London.

15. Bowling A (2009) Research Methods in Health. Open University Press, Maidenhead.

16. Maxwell JA (2009) Designing a qualitative study. The Sage Handbook of Applied Social Research Methods. Sage Publications Ltd, Thousand Oaks, CA

17. Faltermaier $T$ (1997) Why public health research needs qualitative approaches: subjects and methods in change. Eur J Public Health 7: 357-363.

18. Snape D, Spencer L (2003) The foundations of qualitative research. Qualitative Research Practice. Sage Publications Ltd, London.

19. Cotterill N (2011) Quality of life issues in continence care. Nurs Stand 26: 51 56.

20. Oppenheim AN (1992) Questionnaire Design, Interviewing and Attitude Measurement. Continuum, London.

21. Boynton PM (2004) Administering, analysing, and reporting your questionnaire. BMJ 328: 1372-1375.

22. de Vaus DA (1996) Surveys in Social Research. UCL Press, London.

23. van Abswoude AH, van der Ark LA, Sijtsma K (2004) A comparative study of test data dimensionality assessment procedures under nonparametric IRT model. Appl Psychol Measurement 28: 3-24.

24. Ostini R (2010) Measuring conceptualisations of morality: or how to invent a construct and measure it too. The Sage Handbook of Measurement, Sage, London.

25. McDoland RP (1982) Linear Versus Models in Item Response Theory. Appl Psychol Measurement 6: 379-396.

26. Ritchie J, Lewis J (2003) Qualitative Research Practice: A Guide for Social Science Students and Researchers. Sage Publications Ltd, London.

27. Patton MQ (2002) Qualitative Research and Evaluation Methods. Sage Publications Ltd, London.

28. Regmi K, Naidoo J, Pilkington P (2010) Understanding the processes of translation and transliteration in qualitative research. Int J Qual Methods 9: 1626.

29. Mason J (2002) Qualitative Researching. Sage Publications Ltd, London.

30. Borrill CS, Carletta J, Carter AJ, Dawson JF, Garrod S, et al. (2000) The Effectiveness of Health Care Teams in the National Health Service. DOH Fina Report.

31. West M, Dawson J, Admasachew L, Topakas A (2011) NHS staff management and health service quality. Results from the NHS Staff Survey and Related Data.

32. Ministry of Health (2002) Policy Paper on Decentralisation. Nepal.

33. Connolly T, Conlon EJ, Deutsch SJ (1980) Organizational effectiveness: a multi-disciple-constituency approach. Acad Management Rev 5: 211-217.

34. Aiken LH, Sloane DM, Clarke S, Poghosyan L, Cho E, et al. (2011) Importance of work environments on hospital outcomes in nine countries. Int J Qual Health Care 23: 357-364.

35. Mpinga EK, Chastonay P (2011) Satisfaction of patients: a right to health indicator. Health Policy 100: 144-150.

36. World Health Organisation (2005) Health related quality of life: what it is and how should we measure it? Soc Sci Med 41: 1403-1409.

37. Rapley M (2003) Quality of Life Research: A Critical Introduction. Sage Publications Ltd, London.

38. Leatherman S, Ferris TG, Berwick D, Omaswa F, Crisp N (2010) The role of quality improvement in strengthening health systems in developing countries. Int J Qual Health Care 22: 237-243. 
Citation: Regmi K (2012) Effective Health Services: Perspectives and Perceptions of Health Service Users and Healthcare Practitioners. Primary Health Care: Open Access 2:117. doi:10.4172/2167-1079.1000117

Page 7 of 7

\begin{tabular}{|c|c|c|c|c|c|c|c|}
\hline Statements & Strongly Agree & Agree & Undecided & Disagree & Strongly Disagree & Response average & Test Statistical \\
\hline $\begin{array}{l}\text { I can access any health services that I } \\
\text { want/need right away }\end{array}$ & 50 & 47 & - & 2 & 1 & 1.57 & $\begin{array}{l}X^{2}=88.56, \mathrm{df}=3, p=000 \\
{[\text { mean: } 1.57, \mathrm{SD}: 0.700]}\end{array}$ \\
\hline $\begin{array}{l}\text { Health service providers (doctors, health } \\
\text { assistants, nurses and other health work- } \\
\text { ers) need to be more thorough in training } \\
\text { and in examining me. }\end{array}$ & 45 & 46 & - & 9 & 0 & 1.73 & $\begin{array}{l}X^{2}=26.66, \mathrm{df}=2, p=000 \\
\text { [mean: } 1.73, \mathrm{SD}: 0.863]\end{array}$ \\
\hline $\begin{array}{l}\text { It is easy for me/my children to get health- } \\
\text { care (including medical, nursing, surgical } \\
\text { etc) in an emergency. }\end{array}$ & 41 & 38 & 1 & 12 & 8 & 2.08 & $\begin{array}{l}X^{2}=66.70, \mathrm{df}=2, p=000 \\
{[\text { mean:2.08, SD: } 1.27]}\end{array}$ \\
\hline $\begin{array}{l}\text { Health service providers (doctors, health } \\
\text { assistants, nurses and other health work- } \\
\text { ers) are good at explaining the reasons for } \\
\text { my health needs. }\end{array}$ & 40 & 35 & - & 13 & 12 & 2.22 & $\begin{array}{l}X^{2}=25.52, \mathrm{df}=3, p=000 \\
{[\text { mean:2.22, SD: } 1.40]}\end{array}$ \\
\hline $\begin{array}{l}\text { I am kept waiting for a long time when I am } \\
\text { at the health service provider's (doctors, } \\
\text { health assistants, nurses and other health } \\
\text { workers) door. }\end{array}$ & 32 & 38 & 1 & 26 & 3 & 2.30 & $\begin{array}{l}X^{2}=57.70, \mathrm{df}=4, p=000 \\
\text { [mean: } 2.30, \mathrm{SD}: 1.25]\end{array}$ \\
\hline $\begin{array}{l}\text { It's hard for me to get healthcare/service at } \\
\text { short notice. }\end{array}$ & 29 & 55 & - & 11 & 5 & 2.08 & $\begin{array}{l}X^{2}=60.48, \mathrm{df}=4, p=000 \\
{[\text { mean: } 2.08, \mathrm{SD}: 1.08]}\end{array}$ \\
\hline $\begin{array}{l}\text { The office hours (hospital, health centre, } \\
\text { health post/sub-health post) where I get } \\
\text { healthcare are convenient (good) for me. }\end{array}$ & 33 & 27 & - & 37 & 3 & 2.50 & $\begin{array}{l}X^{2}=27.84, \mathrm{df}=3, p=000 \\
\text { [mean: } 2.50, \mathrm{SD}: 1.36 \text { ] }\end{array}$ \\
\hline $\begin{array}{l}\text { The office (hospital, health centre, health } \\
\text { post/sub-health post) where I get healthcare } \\
\text { should be open more hours than it is. }\end{array}$ & 28 & 32 & - & 25 & 15 & 2.67 & $\begin{array}{l}X^{2}=6.32, \mathrm{df}=3, p=.097 \\
{[\text { mean: } 2.67, \mathrm{SD}: 1.48]}\end{array}$ \\
\hline $\begin{array}{l}\text { I have easy access to the specialised health } \\
\text { professionals (doctors/specialists) I need. }\end{array}$ & 32 & 16 & - & 34 & 18 & 2.90 & $\begin{array}{l}X^{2}=10.40, \mathrm{df}=3, p=015 \\
{[\text { mean:2.98, SD: } 1.58]}\end{array}$ \\
\hline $\begin{array}{l}\text { Places where I get healthcare are more } \\
\text { conveniently located }\end{array}$ & 39 & 34 & - & 19 & 8 & 2.23 & $\begin{array}{l}X^{2}=24.08, \mathrm{df}=3, p=000 \\
{[\text { mean:2.23, SD:1.35] }}\end{array}$ \\
\hline $\begin{array}{l}\text { If I have a health-related question/problem, } \\
\text { I can reach a health service provider (doc- } \\
\text { tor, health assistant, nurse and other health } \\
\text { worker) for help with any problem }\end{array}$ & 48 & 35 & - & 13 & 4 & 1.90 & $\begin{array}{l}X^{2}=48.56, \mathrm{df}=3, p=000 \\
\text { [mean: } 1.90, \mathrm{SD}: 1.16]\end{array}$ \\
\hline $\begin{array}{l}\text { I am able to get healthcare whenever I } \\
\text { need it }\end{array}$ & 38 & 38 & - & 20 & 4 & 2.14 & $\begin{array}{l}X^{2}=61.50, \mathrm{df}=4, p=000 \\
\text { [mean:2.14, SD: } 1.23]\end{array}$ \\
\hline $\begin{array}{l}\text { I am fully satisfied with the healthcare } \\
\text { services I receive with respect to my values } \\
\text { and expectations }\end{array}$ & 29 & 33 & - & 16 & 22 & 2.69 & $\begin{array}{l}X^{2}=61.50, \mathrm{df}=3, p=079 \\
{[\text { mean:2.69, SD:1.56 ] }}\end{array}$ \\
\hline $\begin{array}{l}\text { I am fully involved in planning local health- } \\
\text { care services }\end{array}$ & 20 & 18 & 2 & 27 & 33 & 3.35 & $\begin{array}{l}X^{2}=27.30, \mathrm{df}=4, p=000 \\
{[\text { mean:3.35, SD:1.57] }}\end{array}$ \\
\hline $\begin{array}{l}\text { The local health service plans have fully } \\
\text { incorporated the problems or concerns of } \\
\text { the local community }\end{array}$ & 20 & 32 & - & 17 & 31 & 3.07 & $\begin{array}{l}X^{2}=6.96, \mathrm{df}=3, p=073 \\
{[\text { mean: } 3.07, \mathrm{SD}: 1.59]}\end{array}$ \\
\hline $\begin{array}{l}\text { We/l have a great role in the planning and } \\
\text { decision-making process }\end{array}$ & 23 & 19 & - & 20 & 38 & 3.31 & $\begin{array}{l}X^{2}=9.36, \mathrm{df}=3, p=025 \\
{[\text { mean: } 3.31, \mathrm{SD}: 1.662]}\end{array}$ \\
\hline $\begin{array}{l}\text { The current local health services/plans } \\
\text { have addressed the healthcare needs of } \\
\text { the people }\end{array}$ & 18 & 44 & 1 & 14 & 23 & 2.80 & $\begin{array}{l}X^{2}=49.30, \mathrm{df}=4, p=000 \\
{[\text { mean:2.80, SD:1.48 ] }}\end{array}$ \\
\hline $\begin{array}{l}\text { I feel that the health services have equally } \\
\text { addressed the issues of disability, handi- } \\
\text { caps, gender differences, equity etc }\end{array}$ & 32 & 47 & - & 15 & 6 & 2.16 & $\begin{array}{l}X^{2}=39.76, \mathrm{df}=3, p=000 \\
{[\text { mean:2.16, SD:1.20] }}\end{array}$ \\
\hline $\begin{array}{l}\text { All health services I receive are appropriate } \\
\text { to me/my family }\end{array}$ & 49 & 48 & - & 3 & - & 1.57 & $\begin{array}{l}X^{2}=41.42, \mathrm{df}=2, p=000 \\
{[\text { mean:1.57, SD: .655] }}\end{array}$ \\
\hline $\begin{array}{l}\text { The services outcomes (cure, treatment) } \\
\text { are positive, therefore I receive fully conve- } \\
\text { nient care (continuity of care) }\end{array}$ & 48 & 49 & - & 3 & - & 1.58 & $\begin{array}{l}X^{2}=41.42, \mathrm{df}=2, p=000 \\
\text { [mean: } 1.58, \mathrm{SD}: .654 \text { ] }\end{array}$ \\
\hline
\end{tabular}

Appendix 1: Summary results of questionnaires - descriptive analysis. 